\title{
Determination of Strouhal Numbers at High Reynolds
}

\section{Numbers}

\author{
Jorge Lassig and Claudia Palese \\ Faculty of Engineering, Universidad Nacional del Comahue, Neuquén 8300, Argentina
}

\begin{abstract}
Leeward of natural elevations, like mountains and hills, the air flow becomes turbulent and often times damaging and hazardous to aviation and downwind populations. There is currently a trend for massive construction projects, the result of which are megastructures that behave similarly to these natural elevations and create analogous turbulence conditions. Examples five mega projects were analyzed, and it was estimated that the Reynolds number variation in these buildings, is from $6.10^{8}$ and $7.10^{9}$, for winds between $10 \mathrm{~m} / \mathrm{s}$ and $50 \mathrm{~m} / \mathrm{s}$. In this work, the authors present a first numerical approach to this phenomenon by calculating the Strouhal numbers induced by winds blowing against large-volume bodies, in the range of high Reynolds numbers. For this study, satellite images depicting von Kármán cloud streets leeward of isolated islands were used. The methodology employed was based on a satellite image where streets watch von Kármán vortex, from NOAA-ARL (National Oceanic and Atmospheric Administration-Air Resource Laboratory) prognosis was obtained for a grid point near the island, then determined the inversion layer and meteorological data (wind, temperature and pressure), was measured from the satellite image the distances separating the vortices to calculate the period, the Reynolds number and Strouhal. The studied results of the cases are displayed graphically, where it is possible to observe a data dispersion as well as a rising trend of the Strouhal number as the Reynolds number increases.
\end{abstract}

Key words: Wind, vortex, Strouhal numbers, high Reynolds numbers, building.

\section{Introduction}

Several urban projects involving the construction of megastructures are currently being proposed and may be realized in the near future, partly as a response to super population in densely populated cities and partly spurred by the excessive cash flow generated by the oil and gas industry in certain countries. Among these projects, it is worth mentioning the following:

(1) Sky City 1000: An urban futurist project aimed at helping overcome major congestion and lack of green space in Tokyo. It consists of a skyscraper $1,000 \mathrm{~m}$ tall and $400 \mathrm{~m}$ wide at the base, with a total floor area of $8 \mathrm{~km}^{2}$. It would house between 35,000 and 36,000 full-time residents [1];

(2) Termite: A mega-building with 3,600 m height and a 1,600 m wide base, inspired in nature, and it resembles the termite nest structure (hence its name).

Corresponding author: Jorge Lassig, Dr., research fields: wind engineering and building aerodynamics. E-mail: jorge.lassig@fain.uncoma.edu.ar.
It would have a housing capacity of up to $1,000,000$ people [2];

(3) Shimizu TRY 2004 Mega-City Pyramid: A proposed construction project to be developed over Tokyo Bay. The structure would be $2,004 \mathrm{~m}$ tall and 2,000 m wide at base, and capable of housing 750,000 residents as well as other 800,000 people working for the offices and commercial facilities within the structure [3];

(4) Crystal Island: A building project to be located on the Nagatino Peninsula, edged by the Moscow River. The structure is planned to have a $620 \mathrm{~m}$ wide base and a height of $450 \mathrm{~m}$ [4];

(5) Golden Dome: A skyscraper in Dubai planned to be $500 \mathrm{~m}$ in height and $200 \mathrm{~m}$ in diameter [5].

Essentially, phenomena fluid-structure interaction is caused by the pressure forces from the flow around a structure resulting in a deformation of the structure, which in turn alters the flow in a dynamic way.

In particular, vibrations generated by vortex 
shedding are of practical interest to civil engineering such as bridges or tall buildings.

The significance of vortex-induced vibrations and the complexity of the cross-wind forcing mechanisms have led to a considerable amount of research work, either experimental or theoretical.

But the vortex shedding at high Reynolds numbers, there is no information, it is difficult to reproduce in a wind tunnel.

These megastructures are subject to winds within and above the atmospheric boundary layer, generating very high Reynolds numbers of the order of $10^{8}-10^{9}$, as shown in Table 1 . Tests could not be run at scale because the reduction of the prototype size entails the increase of wind speed intensity, at high speed scenarios, compressibility phenomena start taking place, rendering the tests void.

Satellite images taken in the early 1960s showed that certain flow patterns similar to von Kármán vortex streets formed in clouds above certain islands and under given meteorological conditions. Since then, atmospheric sciences researchers have focused their efforts on analyzing and explaining this phenomenon.

The conclusion researchers have come to is that such flow patterns clearly involve vortices caused by the wind incidence on the topography of the islands, with associated fluid dynamic structures of the order of $10^{8}-10^{10}$ Reynolds numbers.

These vortex wakes made visible by clouds may be quantified by means of the Strouhal number, which renders the information required to characterize the non-compressible flow patterns developing in the wake of large objects.

Table 1 Reynolds number range calculated for $10-50 \mathrm{~m} / \mathrm{s}$ winds, at standard air conditions and with the building base width as the characteristic dimension.

\begin{tabular}{ll}
\hline Mega project & Reynolds numbers \\
\hline Sky City & $2.6 \times 10^{8}-1.3 \times 10^{9}$ \\
Termita & $1.0 \times 10^{9}-5.3 \times 10^{9}$ \\
Shimizu TRY 2004 & $1.3 \times 10^{9}-6.6 \times 10^{9}$ \\
Cristal Island & $4.1 \times 10^{8}-2.0 \times 10^{9}$ \\
Golden Dome & $1.3 \times 10^{8}-6.6 \times 10^{8}$ \\
\hline
\end{tabular}

Atmospheric vortex streets leeward of certain islands were first observed in satellite imagery by Hubert and Krueger [6]. A few years later, Chopra and Hubert [7] analysed these cloud vortex patterns in the wake of Madeira Island using polar-orbiting satellite data. These wake vortices bore a strong resemblance with von Kármán vortex streets, both in shape and formation process. By analysing their characteristics (periods, amplitude and displacement), they observed that the vortices occurring leeward of islands did not mix with the surrounding atmospheric flow and that the momentum transfer (or energy dissipation) between this vortex trail and the basic background flow was minimum. As a result, these vortices lining up into streets had a relatively long lifetime and persisted for tens of kilometres downstream from the island. It was also observed that the size of the vortices increased with time and downwind while the intensity in the vortex core decreased. In time, vortices with opposite rotation interacted downwind of the obstacle in such a way that eventually the vortex street broke down.

It was soon demonstrated that such eddy patterns could be explained in terms of von Kármán's and Rubach's [8] original theories. These island-generated von Kármán vortex streets have been observed from different types of satellites as well as from manned spacecraft.

Castro et al. [9] studied through satellite images and experiments in laboratories, the von Karman vortex streets in conical bodies.

Young and Zawislak [10] analyzed 30-image sample from the Aqua and Terra Moderate Resolution Imaging Spectroradiometer satellites, to obtain the ratio of the cross-street spacing to the crosswind width of the island. The result is that the aspect ratio is larger than predicted as it is the dimensionless width ratio. The differences are consistent with the turbulent diffusion of vorticity in the wake of the island. The vortex streets more closely follow inviscid theory close to the island, with vortex expansion taking place 
a few vortex diameters downwind of the island.

$\mathrm{Li}$ et al. [11] observed in RADARSAT-1 SAR (synthetic aperture radar) images of Atmospheric Vortex Street off Aleutian Volcanic Islands, Alaska. The SAR measurements not only show the Atmospheric Vortex Street spatial structure in a much higher resolution than that of weather satellite (both polar and geostationary) but also can quantitatively provide the surface wind field.

On the other hand, the search of finding the values of the number Strouhal to high numbers of Reynolds for cylinders, has many antecedents, from the works of Roshko [12], until those of Zan [13], but none superior at 10 million, and all with the limitations of not violating the hypotheses of incompressible flow.

The purpose of this study is to obtain a first approach to the macroturbulence problem that will be generated behind the megastructures mentioned above, by defining a Strouhal-Reynolds number relationship for natural obstacles, like isolated mountains and hills.

\section{Methods}

Vortex trails predominantly form in areas with stratocumulus clouds or cumulus clouds with limited vertical development, in areas dominated by subtropical anticyclones (which provide great stability) or in areas where stratocumulus clouds are capped by a strong temperature inversion.

Temperature inversion has been determined by using sounding data (Table 2) to detect the air layer in which the temperature increases with height. This layer is an extremely stable air mass that prevents upward air motion. Below the inversion layer, the atmospheric flow is forced to move horizontally with very weak vertical motion, enabling cumuliform clouds to develop, but in horizontal sheet-like layers.

When the inversion layer lies below an island or a mountain top that is situated in this flow, the atmospheric flow below the inversion will be forced to flow around it instead of passing over. As a result,
Table 2 Sounding data obtained on April 30, 2001 over the Rishiri-to Island, Japan.

\begin{tabular}{rccc}
\hline Height $(\mathrm{m})$ & Temp $\left({ }^{\circ} \mathrm{C}\right)$ & Direction $\left({ }^{\circ}\right)$ & Speed $(\mathrm{m} / \mathrm{s})$ \\
\hline 0 & 1.7 & & \\
16.0 & 1.7 & 0.0 & 0.0 \\
188.0 & -0.1 & 81.3 & 9.7 \\
806.0 & -4.2 & 82.1 & 9.8 \\
$1,479.0$ & -0.8 & 42.3 & 8.8 \\
$3,018.0$ & -6.2 & 358.2 & 13.5 \\
$5,578.0$ & -20.8 & 358.7 & 30.4 \\
$7,194.0$ & -31.5 & 351.9 & 39.7 \\
$9,166.0$ & -46.0 & 355.8 & 48.7 \\
$10,359.0$ & -53.8 & 351.9 & 50.1 \\
$11,776.0$ & -57.7 & 344.9 & 36.4 \\
$13,597.0$ & -55.5 & 333.8 & 18.9 \\
$16,182.0$ & -56.6 & 309.1 & 12.1 \\
$20,586.0$ & -57.2 & 319.3 & 3.9 \\
$26,428.0$ & -51.9 & 48.5 & 3.0 \\
\hline
\end{tabular}

vortices exhibiting mesoscale dimensions of the order of a few tens of kilometres may be formed.

Thus, a pair of counter-rotating vortices is created around the island, with one vortex being shed on each side of the topographic barrier. If the layer where this takes place is cloudy, vortices become clearly visible to satellites.

An study by Epifanio and Durran [14] also indicated that when the inversion occurs in a layer that is higher than the obstacle or island top, the air acting on the system may move upwards and pass over the topographic barrier, generating mountain waves and causing vortices to rapidly disappear or dissipate.

The study methods included the following steps, based on a satellite image depicting von Kármán vortex streets: plotting the forecast sounding data (Fig. 1) for a grid point near the island (taken form NOAA ARL [15]); determining the inversion layer and the meteorological data (wind, temperature and pressure); measuring the distances between vortices on the satellite picture, in order to calculate the period and the Reynolds and the Strouhal numbers.

As an example of the study methods applied, from the examination of the Skew-T (Fig. 1) plotted based on the sounding data taken on April 30, 2001 (Table 2), temperature inversion was found to take place in the 


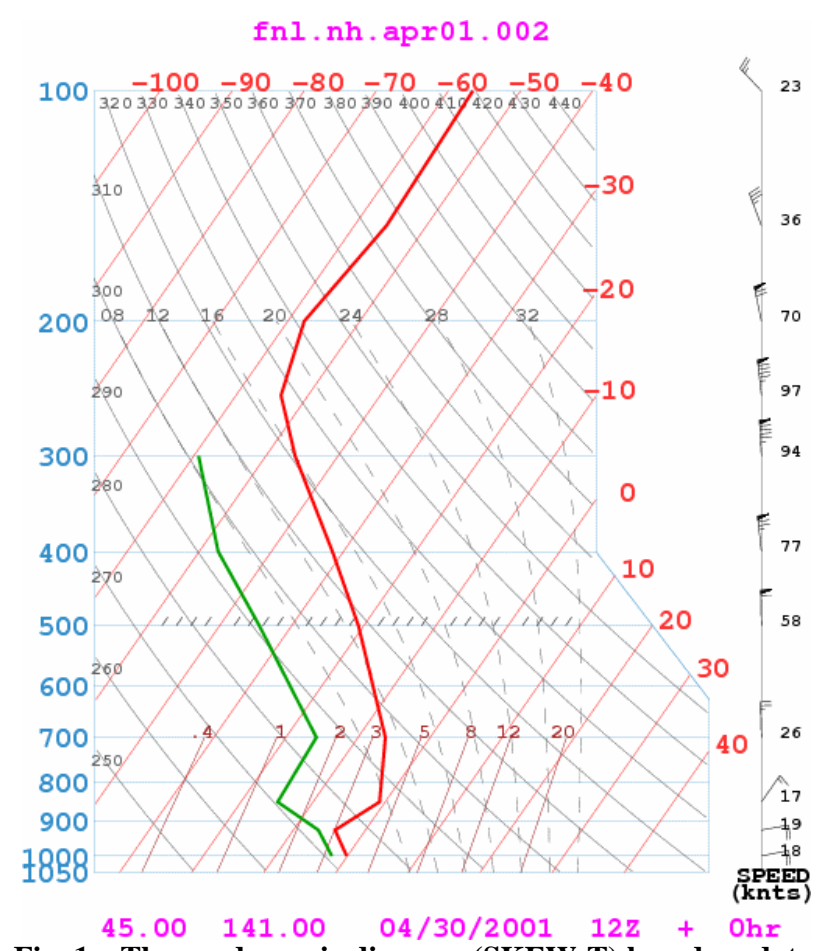

Fig. 1 Thermodynamic diagram (SKEW-T) based on data taken on April 30, 2001 over Rishiri-to Island, Japan (taken from NOAA ARL).

layer extending from $806 \mathrm{~m}$ to $1,479 \mathrm{~m}$ over the Rishiri-to Island, Japan. The strong inversion bounds a zone in lower layers where vortex streets may form. Mean wind was about $9.8 \mathrm{~m} / \mathrm{s}$ essentially easterly. This layer was below the island height (1,721 $\mathrm{m}$ at the highest peak).

Fig. 2 is an image taken during space shuttle mission STS-100 on April 30, 2001, showing von Kármán vortex streets created by the Rishiri-to Island in Japan [16].

Strouhal and Reynolds numbers were calculated using the nomenclature proposed by Atkinson [17], based on the observations of satellite images (Fig. 3), in this figure, $D$ is obstacle width (island or mountain), $a$ is distance between the centre of adjacent vortices, $h$ is spacing between the centre of adjacent counter-rotating vortices, and $V$ is incident wind velocity.

The Reynolds number was defined as:

$$
\operatorname{Re}=\frac{V \cdot D}{v}
$$

where, $v$ is the air kinematic viscosity.

The period $T$ was calculated as:

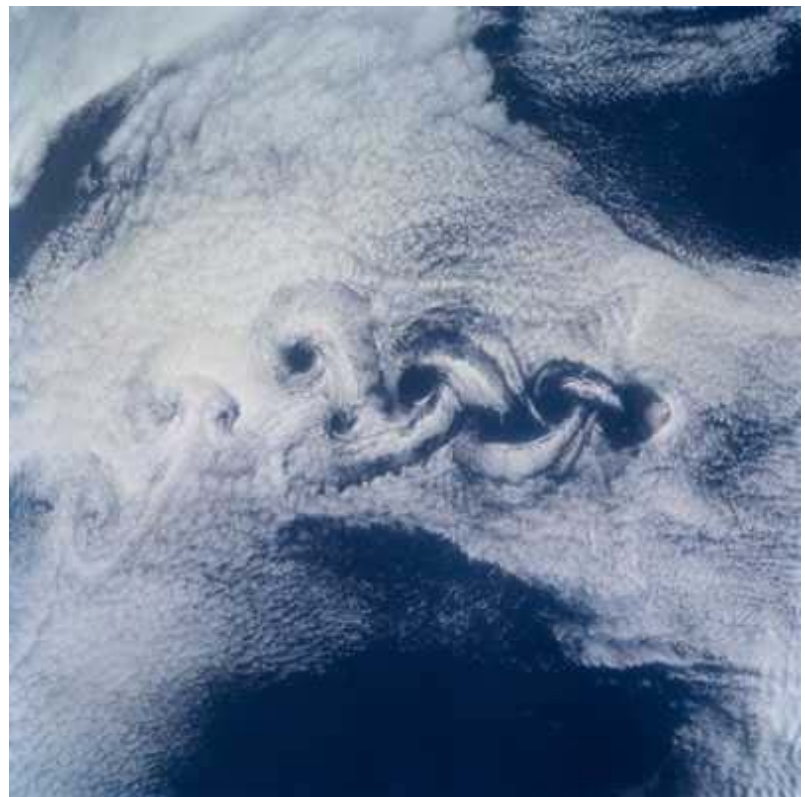

Fig. 2 A von Kármán vortex street formed by Rishiri-to Island, Japan. Picture taken during space shuttle mission STS-100 on April 30, 2001.

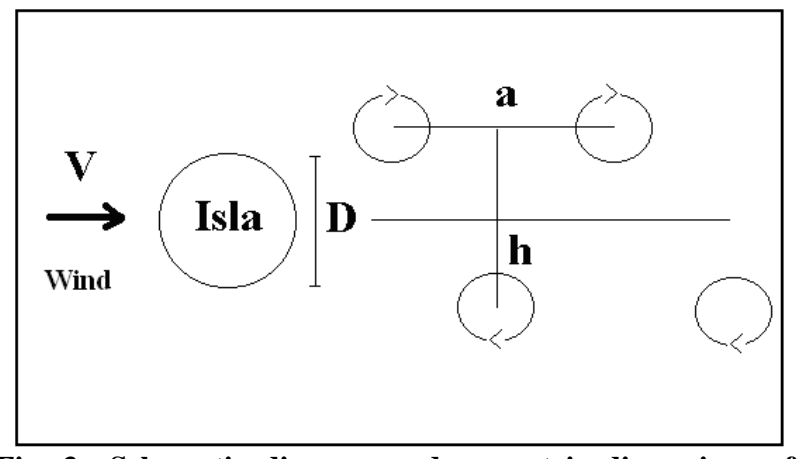

Fig. 3 Schematic diagram and geometric dimensions of island-generated von Kármán vortex streets.

$$
T=\frac{a}{V}
$$

The frequency $f$ was calculated as:

$$
f=\frac{1}{T}
$$

The Strouhal number was given by:

$$
S t=\frac{f . D}{V}
$$

\section{Results and Discussions}

This first approach included only fourteen cases studied from satellite imagery that showed von Kármán vortex streets formed on the leeward side of islands (Table 3). 
Table 3 Islands for which Reynolds and Strouhal numbers were calculated for vortex streets.

\begin{tabular}{lll}
\hline Island & Re & St \\
\hline Aleutian (small) & $6.0 \times 10^{8}$ & 0.158 \\
Aleutian (medium) & $1.0 \times 10^{9}$ & 0.26 \\
Guadalupe & $3.0 \times 10^{9}$ & 0.135 \\
Robinson Crusoe & $4.0 \times 10^{9}$ & 0.30 \\
Guadalupe & $5.0 \times 10^{9}$ & 0.104 \\
Guadalupe & $6.0 \times 10^{9}$ & 0.181 \\
Aleutian (large) & $7.0 \times 10^{9}$ & 0.379 \\
Gran Canaria & $9.0 \times 10^{9}$ & 0.39 \\
Rishiri-to & $1.0 \times 10^{10}$ & 0.229 \\
Cabo Verde (Sao Nicolau) & $1.0 \times 10^{10}$ & 0.51 \\
Cabo Verde (Sao Antao) & $1.0 \times 10^{10}$ & 0.25 \\
Cabo Verde (Sao Nicolau) & $2.0 \times 10^{10}$ & 0.41 \\
Madeira & $2.0 \times 10^{10}$ & 0.47 \\
Tenerife & $2.0 \times 10^{10}$ & 0.828 \\
\hline
\end{tabular}

Islands were first grouped by geometric shape. Islands with an important mountain or volcano were considered to be cone-shaped bodies against which the wind blew (Fig. 2). The remaining islands were rectangular in shape (Fig. 4), but in some cases the wind blew parallel to the island's longest side (Fig. 5).

The results given in Table 3 are displayed graphically in Fig. 6, where it is possible to observe a data dispersion as well as a rising trend of the Strouhal number as the Reynolds number increases. The curve of this rising trend has been plotted on the graph.

It has been interesting to compare the present results with those yielded by other studies where the same type of vortices was calculated but using other means, like calculation from Doppler radars on land surface. Such is the case of the study by Shun et al. [18], who measured an event of von Kármán vortex streets shedding from the mountains that surround the Hong Kong International Airport (Lantau Island) on August 2, 1997. In this case, the Strouhal number was 0.209 at a Reynolds number of $3.3 \times 10^{9}$.

Also Chan and Shun [19] studied vortex shedding events occurring in the vicinity of the same airport. On January 27, 2002, they observed von Kármán vortex streets downstream of Castle Peak, where the Strouhal number was 0.19 at a Reynolds number of $1.2 \times 10^{9}$. On January 19,2005 , they observed the

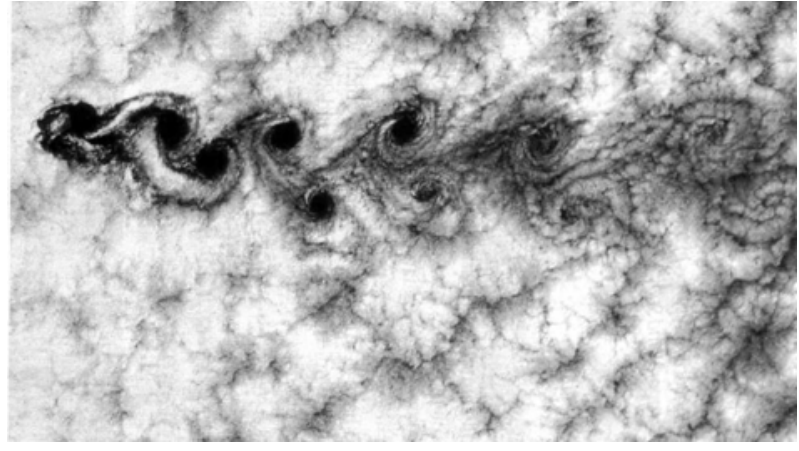

Fig. 4 Alexander Selkirk Island [20].

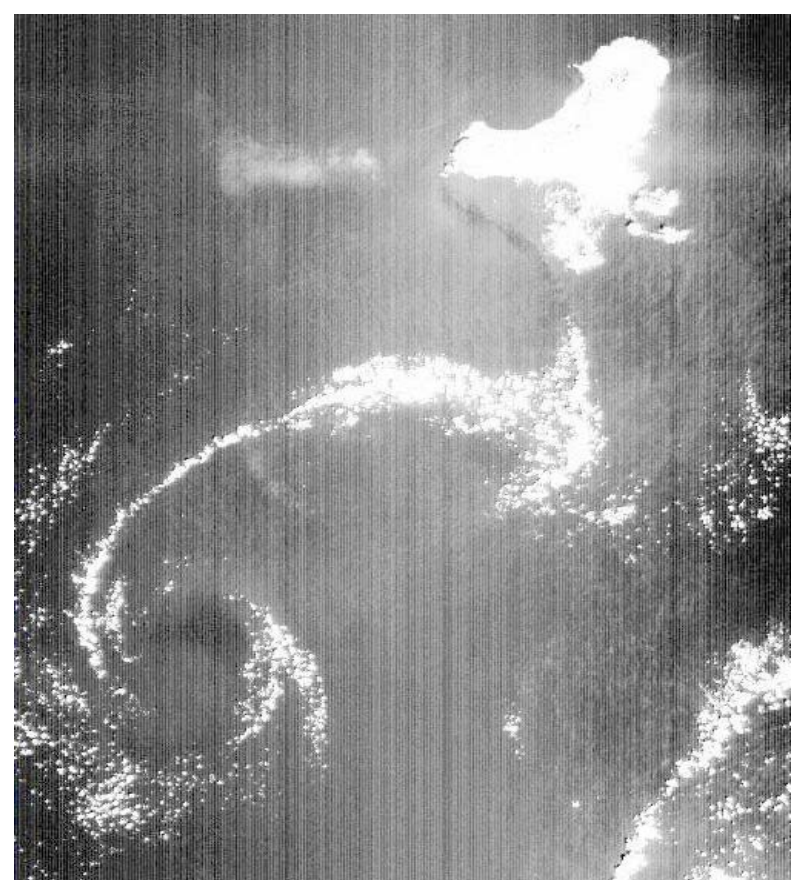

Fig. 5 Satellite images of El Hierro Island, from SAC-C [21]. Alexander Selkirk Island.

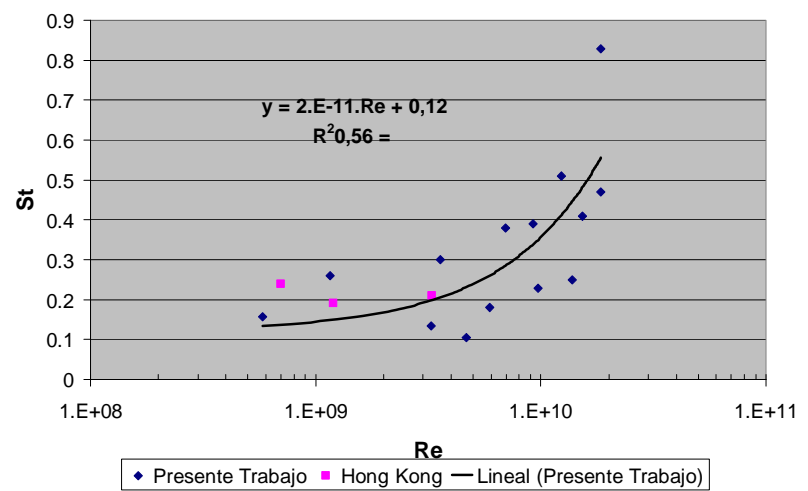

Fig. 6 Depicts the data points corresponding to the present study results and the values obtained from Refs. [18, 19] (red square data points).

same flow pattern downstream of Lo Fu Tau (cone shaped) with a Strouhal number of 0.24 at a Reynolds 
number of $7 \times 10^{8}$.

\section{Conclusions}

A Strouhal-Reynolds number relationship has been defined for natural obstacles like hills and mountains, based on the analysis of vortical cloud patterns occurring leeward of isolated islands as depicted on different types of satellite images.

The correlation of the best-fit curve is not exact $\left(R^{2}\right.$ $=0.56$ ), probably due to the following factors implicit in the calculation method: The wind intensity value was taken from a forecast numerical model (it was not the actual observed value), vortex periods were long and slightly variable, since 6 vortices to 18 vortices could be observed in one single street and with different spacing, and for this reason only the average value for the first 4 vortices was computed in this study.

However, the results yielded by this study match those obtained by other researchers who used other measuring techniques (Doppler radar) for determining von Kármán vortex streets.

From the analysis of the 14 cases included in this study, it has been noted that when the Reynolds number are in the range of $10^{8}$ to $4.10^{9}$, the Strouhal numbers varied mildly from 0.1 to 0.3 , whereas with Reynolds numbers were greater than $4.10^{9}$, the Strouhal number increased rapidly.

Making an analogy between the geometric shapes of the islands studied and geometry of future mega-buildings, could be applied to determine the frequencies induced wind from the Strouhal number.

From the results obtained in Fig. 6, it shows that for a mega-building rectangular geometry, there is a significant variation in Strouhal number, if the wind hits perpendicular (green marks) or parallel (blue markings) to the longitudinal axis of the building, which would cause great variations in the frequency induced by the wind on the building.

\section{Acknowledgments}

The present research has been supported by the Universidad Nacional del Comahue, and ANCyT through Picto Cin II 2010-0085.

\section{References}

[1] Sky City Web Site, www.takenaka.co.jp/takenaka_e/ techno/63_sky/ 63_sky.htm (accessed Mar. 18, 2008).

[2] Termite Web Site, www.inhabitat.com/2008/04/03/ ultima-tower-the-vertical-green-city-that-works-like-a-tre e (accessed Sep. 18, 2007).

[3] Shimizu TRY 2004 Mega-City Pyramid Web Site, www.skyscrapercity.com/showthread.php?p=18642092 (accessed Mar. 18, 2008).

[4] Crystal Island Web Site, www.fosterandpartners.com/ Projects/1496/Default.aspx (accessed Mar. 18, 2008).

[5] Golden Dome Web Site, www.gotodubai.net /projects/crystal-dome.html (accessed Mar. 18, 2008).

[6] L.F. Hubert, A.F. Krueger, Satellite pictures of mesoscale eddies, Mon. Wea. Rev. 90 (1962) 457-463.

[7] K.P. Chopra, L.F. Hubert, Mesoscale eddies in wakes of islands, J. Atmos. Sci. 22 (1965) 652-657.

[8] T. von Karman, H. Rubach, About mechanism of resistence in liquid and air, Physik Zeitschrift 13 (1912) 49-59.

[9] I. Castro, S. Vosper, M. Paisley, P. Hayden, Vortex shedding behind tapered obstacles in neutral and stratified flow, Dynamics of Atmospheres and Oceans 34 (2001) 145-163.

[10] G.S. Young, J. Zawislak, An observational study of vortex spacing in island wake vortex streets, Monthly Weather Review 134 (2006) 2285-2294.

[11] X.F. Li, W.Z. Zheng, C.Z. Zou, W.G. Pichel, A SAR Observation and numerical study on ocean surface imprints of atmospheric vortex streets, Sensors 8 (2008) 3321-3334.

[12] A. Roshko, Experiments on the flow past a circular cylinder at very high reynolds number, Journal of Fluid Mechanics 10 (1961) 345-356.

[13] S.J. Zan, Experiments on circular cylinders in crossflow at Reynolds numbers up to 7 million, Journal of Wind Engineering and Industrial Aerodynamics 96 (2008) 880-886.

[14] C.C. Epifanio, D.R. Durran, Lee-vortex free-slip stratified flow over ridges, Part I: Comparison of weakly nonlinear inviscid theory and fully nonlinear viscous simulations, J. Atmos. Sci. 59 (2002) 1153-1165.

[15] NOAA ARL Web Site, http://www.arl.noaa.gov/ ready.htmldate (accessed Sep. 18, 2007). 
[16] Rishiri-to Island Web site, Site http://spaceflight.nasa.gov/gallery/images/shuttle/sts-100/ lores/sts100-710-182.jpg (accessed Sep. 18, 2001).

[17] B.W. Atkinson, Meso-scale Atmospheric Circulations, Academic Press, London, 1981, p. 495.

[18] C.M. Shun, S.Y. Lau, O.S.M. Lee, Terminal Doppler weather radar observation of atmospheric flow over complex terrain during tropical cyclone passages, Journal of Applied Meteorology 42 (2003) 1697-1710.
[19] P.W. Chan, C.M. Shun, Numerical simulation of vortex shedding observed at the Hong Kong international airport using a shallow water model, Croatian Meteorological Journal 40 (2005) 27-30.

[20] Alexander Selkirk Island We Site, www.astrosurf.org/lombry/Documents/nuages-vortex-kar man-alexander-selkirk.jpg (accessed Sep. 18, 2007).

[21] Satellite images of El Hierro Island Web Site, http://catalogos.conae.gov.ar/SAC_C/default3.asp (accessed Apr. 10, 2010). 